\title{
Myocardial dysfunction in treated adult hypopituitarism: a possible explanation for increased cardiovascular mortality
}

\author{
Clinical Department \\ of Cardiology, \\ St Mary's Hospital, \\ London \\ M Shahi \\ D Hackett \\ R A Foale \\ Unit of Metabolic \\ Medicine, St Mary's \\ Hospital, London \\ S A Beshyah \\ P S Sharp \\ D G Johnston \\ Correspondence to \\ Dr Manjit Shahi, Clinical \\ Department of Cardiology, \\ St Mary's Hospital, Praed \\ Street, London W2 1NY. \\ Accepted for publication \\ 30 August 1991
}

Manjit Shahi, Salem A Beshyah, David Hackett, Patrick S Sharp, Desmond G Johnston, Rodney A Foale

\begin{abstract}
Objective-To assess cardiac structure and function in patients with treated hypopituitarism and to determine their relation to the degree of growth hormone deficiency and body composition pattern.

Design-26 patients with treated hypopituitarism were studied by cross sectional and Doppler echocardiography and by exercise testing. The results were analysed and their relation to the degree of growth hormone deficiency and body composition determined.
\end{abstract}

Setting-All tests were performed in the department of cardiology and the unit of metabolic medicine at a tertiary referral centre.

Patients-Patients with hypopituitarism referred for endocrine assessment.

Main outcome measures-Left ventricular mass, left ventricular diastolic function, and exercise capacity in patients with hypopituitarism and their relation to growth hormone deficiency.

Results-Mean (SD) serum concentration of insulin-like growth factor 1 (IGE-1), a measure of growth hormone deficiency, was 82.4 (45) $\mu \mathrm{g} / 1$. Lean body mass calculated by measuring total body potassium was 50 (9) kg. All patients had a normal left ventricular mass index and a normal left ventricular ejection fraction. Eight patients had abnormal left ventricular diastolic function. There was a significant correlation between IGF-1 and left ventricular mass $(r=0.45, p<$ 0.02 ). Lean body mass was also significantly correlated with left ventricular mass $(\mathbf{r}=0.78, \mathbf{p}<0.0001)$ and left ventricular diastolic function $(r=-0.63$, $p<0.01)$. The mean exercise duration was 8.6 (3.6) minutes. There was a significant correlation between serum IGF-1 and the rate-pressure product on exercise $(r=0.47, p<0.01)$. Seven patients had planar ST segment depression $>0.1 \mathrm{mV}$ during exercise testing. In five of these patients there was rapid resolution of ST segment depression immediately after exercise. Two patients developed considerable ST segment depression, and subsequent coronary angiography showed normal coronary arteries. Exercise-induced ST segment depression was not related to the severity or duration of growth hormone deficiency or serum cholesterol concentration.

Conclusions-This study suggests that left ventricular mass and the ratepressure product are related to the degree of growth hormone deficiency, that left ventricular diastolic dysfunction is frequently seen in hypopituitarism, and that these patients may have ischaemiclike ST segment changes during exercise testing. These findings may explain the increased cardiovascular mortality in patients with hypopituitarism and may also have implications for growth hormone replacement therapy in adults.

Patients who develop hypopituitarism in adulthood have conventionally received replacement therapy with thyroxine, cortisone, and sex hormones but not growth hormone. This has in part been because of the limited availability of growth hormone and the belief that growth hormone has no important action once final linear growth has been achieved. ${ }^{1}$ However, growth hormone has now been made available in essentially unlimited amounts and in a pure synthetic form by genetic engineering techniques. Also, recent evidence has suggested that the increased cardiovascular mortality, in particular a high incidence of myocardial infarction and heart failure, seen in patients with treated hypopituitarism may be due to growth hormone deficiency. ${ }^{2}$

Growth hormone is known to be a potent agent affecting anabolism and lipolysis. Adults with growth hormone deficiency are known to have an altered body composition with excess body fat and decreased lean body mass. ${ }^{3}$ This form of change in body composition has been previously shown to be associated with an increased risk of cardiovascular disease in symptom free individuals. ${ }^{45}$ In addition, growth hormone seems to be important in the regulation of plasma lipids, with deficiency of growth hormone often causing hypercholesterolaemia. $^{67}$

The aim of the present study was to assess cardiac structure and function in patients with treated hypopituitarism and to determine their relation to the degree of growth hormone deficiency and body composition pattern.

\section{Patients and methods}

\section{PATIENTS}

Patients recruited into the study had documented hypopituitarism mostly resulting from pituitary or parapituitary tumours treated surgically, with radiotherapy, or with both. All 
had been on hormonal replacement therapy with thyroxine and adrenal and sex steroids, if appropriate, for at least one year. Optimal substitution with thyroxine and adrenal steroids were defined as a total serum thyroxine (T4) within the normal reference range and at least one plasma cortisol value $>350 \mathrm{nmol} / \mathrm{l}$ during the day. In addition, all patients were severely deficient in growth hormone, defined as a growth hormone response of $<5 \mathrm{mU} / 1$ during an insulin induced hypoglycaemia test (serum glucose $<2.2 \mathrm{mmol} / \mathrm{l}$ ) or, if hypoglycaemia was contraindicated, a growth hormone response of $<5 \mathrm{mU} / 1$ in response to $50 \mu \mathrm{g}$ oral clonidine. No patient had previously received growth hormone replacement.

\section{METABOLIC ASSESSMENT}

Lean body mass was calculated from total body potassium $^{8}$ which was measured in a wholebody potassium-40 counter (MRC Cyclotron Unit, Hammersmith Hospital). Serum insulinlike growth hormone factor (IGF-1), a measure of growth hormone deficiency, was measured by radioimmunoassay. ${ }^{9}$ The mean value of IGF-1 in our laboratory in $\mathbf{4 0}$ healthy volunteers was $215(40) \mu \mathrm{g} / 1$.

\section{ECHOCARDIOGRAPHY}

Each patient was examined in the left lateral supine position by cross sectional and Doppler echocardiography with a phased array sector scanner (General Electric Pass 11, 3.5 MHz transducer) in a standardised examination protocol. ${ }^{10}$ Left ventricular septal and posterior wall thickness, and cavity dimensions were measured from the parasternal left ventricular short axis projections at the chordae and papillary muscle junction by cross sectionally
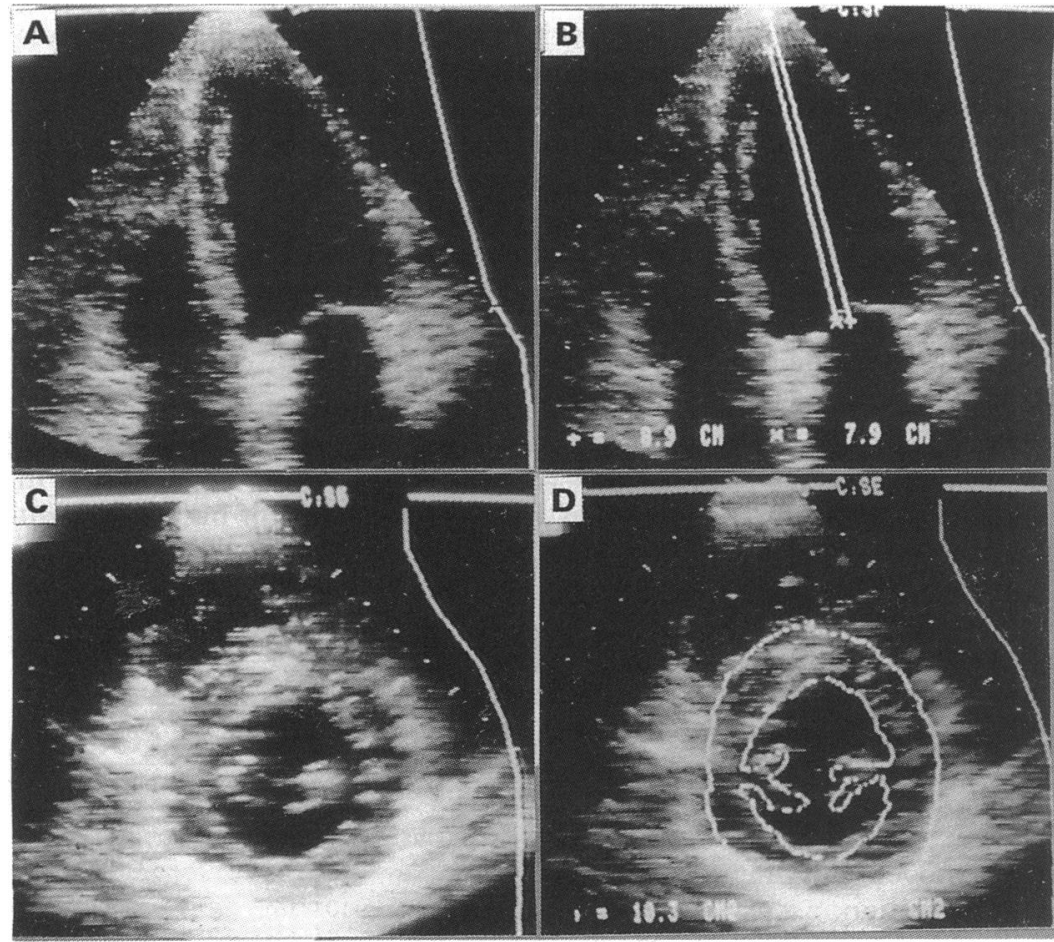

Figure 1 Cross sectional technique for the determination of left ventricular mass. (A) Apical four chamber view, (B) length of left ventricle from mitral annulus to epicardial and endocardial borders, (C) parasternal short axis view, (D) epicardial and endocardial areas measured by planimetry. See text for method of calculation. guided $M$ mode echocardiography. Left ventricular mass was determined by an area $x$ length method which has been previously been validated in humans ${ }^{11}$ with all measurements taken at end diastole and at end expiration. Two echocardiographic views are required to make this calculation: a parasternal short axis view of the left ventricle at the papillary muscle tip level to determine the area of the myocardium and an apical four chamber view that maximises the distance from the mitral valve annulus to the left ventricular apex to determine the length of the ventricle (fig 1). The following formula was used to calculate left ventricular mass: $L V$ mass $=1.04\left(5 / 6 \mathrm{~A}_{1} \mathrm{xl}_{1}-\right.$ $\left.5 / 6 \quad A_{2} \times l_{2}\right)$ where $A_{1}$ and $A_{2}$ represent the epicardial and endocardial areas respectively (measured by planimetry) and $l_{1}$ and $l_{2}$ represent the length of the left ventricle from mital annulus to epicardial and endocardial borders respectively. Left ventricular mass index was determined by dividing the left ventricular mass by the patient's body surface area $(\mathbf{S}=$ $\mathrm{M}^{0.425} \times \mathrm{H}^{0.725} \times 71 \cdot 84$, where $\mathrm{S}=$ body surface area $\left(\mathrm{cm}^{2}\right), M=$ body mass $(\mathrm{kg})$, and $\mathrm{H}=$ height $(\mathrm{cm}))$.

DOPPLER STUDIES

Pulsed Doppler examination of transmitral flow was recorded from the apical four chamber view with reference to the cross sectional echocardiographic image. The sample volume was positioned between the mitral annulus and the tips of the mitral leaflets with the position adjusted to maintain the sample volume at an angle as near parallel to transmitral flow as possible by using the audible signal and spectral velocity display. When the maximum transmitral velocity for the early filling wave was detected, we recorded the velocity profile at $50 \mathrm{~mm} / \mathrm{s}$ with the patient in passive end expiration. The peak flow velocities of the early and atrial waves were measured from the three consecutive cardiac cycles that showed the highest measurable velocity profiles.

The isovolumic relaxation time (IVRT) was measured from the apical five chamber view by placing the continuous wave Doppler beam between the mitral and aortic valve junction. The interval between the end of the aortic velocity envelope and the onset of the early filling wave was taken to represent the isovolumic relaxation time. Abnormal left ventricular diastolic function was defined as follows: IVRT $>82 \mathrm{~ms}$ and $\mathrm{E} / \mathrm{A}$ ratio $<1.5$ between the ages of 20 and 29; IVRT $>92 \mathrm{~ms}$ and $E / A$ ratio $<1.4$ between the ages of 30 and 49; IVRT $>100 \mathrm{~ms}$ and E/A ratio $<0.8$ between the ages of 50 and $59 . .^{1213}$

EXERCISE ASSESSMENT

Symptom-limited, graded multistage treadmill exercise testing according to Bruce's standard protocol $^{14}$ was performed by all patients in a temperature and humidity controlled environment with standard safety precautions. Heart rate and blood pressure were measured at the end of each stage of the protocol and exercise was stopped by symptoms such as leg weakness, shortness of breath, or exhaustion. Data 
Table 1 Patient details

\begin{tabular}{|c|c|c|c|c|c|c|c|c|}
\hline Patient & Sex & $\begin{array}{l}\text { Age } \\
(y r)\end{array}$ & $\begin{array}{l}B M I \\
\left(\mathrm{~kg} / \mathrm{m}^{2}\right)\end{array}$ & $\begin{array}{l}\mathrm{DOH} \\
(y r)\end{array}$ & $\begin{array}{l}\text { Cholesterol } \\
(\mathrm{mmol} / \mathrm{l})\end{array}$ & $\begin{array}{l}\text { Triglyceride } \\
(\text { mmol } / l)\end{array}$ & Diagnosis & $\begin{array}{l}\text { Replacement } \\
\text { therapy }\end{array}$ \\
\hline $\begin{array}{r}1 \\
2 \\
3 \\
4 \\
5 \\
6 \\
7 \\
8 \\
9 \\
10 \\
11 \\
12 \\
13 \\
14 \\
15 \\
16 \\
17 \\
18 \\
19 \\
20 \\
21 \\
22 \\
23 \\
24 \\
25 \\
26\end{array}$ & $\begin{array}{l}\mathbf{M} \\
\mathbf{M} \\
\mathbf{M} \\
\mathbf{M} \\
\mathbf{M} \\
\mathbf{M} \\
\mathbf{M} \\
\mathbf{M} \\
\mathbf{M} \\
\mathbf{M} \\
\mathbf{M} \\
\mathbf{M} \\
\mathbf{M} \\
\mathbf{F} \\
\mathbf{F} \\
\mathbf{F} \\
\mathbf{F} \\
\mathbf{F} \\
\mathbf{F} \\
\mathbf{F} \\
\mathbf{F} \\
\mathbf{F} \\
\mathbf{F} \\
\mathbf{F} \\
\mathbf{F} \\
\mathbf{F}\end{array}$ & $\begin{array}{l}34 \\
59 \\
47 \\
64 \\
59 \\
52 \\
27 \\
45 \\
59 \\
50 \\
44 \\
41 \\
63 \\
53 \\
59 \\
57 \\
47 \\
26 \\
38 \\
41 \\
44 \\
53 \\
49 \\
43 \\
27 \\
41\end{array}$ & $\begin{array}{l}26 \cdot 6 \\
26 \cdot 2 \\
28 \cdot 2 \\
25 \cdot 0 \\
25 \cdot 7 \\
26 \cdot 0 \\
19 \cdot 4 \\
29 \cdot 9 \\
29 \cdot 5 \\
33 \cdot 8 \\
32 \cdot 4 \\
33 \cdot 5 \\
33 \cdot 9 \\
25 \cdot 1 \\
27 \cdot 5 \\
29 \cdot 7 \\
29 \cdot 1 \\
21 \cdot 8 \\
30 \cdot 5 \\
32 \cdot 1 \\
31 \cdot 1 \\
26 \cdot 3 \\
23 \cdot 5 \\
32 \cdot 7 \\
26 \cdot 5 \\
19 \cdot 9\end{array}$ & $\begin{array}{r}15 \\
28 \\
5 \\
9 \\
9 \\
3 \\
6 \\
3 \\
20 \\
6 \\
4 \\
2 \\
1 \\
21 \\
15 \\
1 \\
16 \\
3 \\
3 \\
6 \\
3 \\
6 \\
4 \\
3 \\
4 \\
3\end{array}$ & $\begin{array}{c}8 \cdot 67 \\
7 \cdot 78 \\
9 \cdot 02 \\
6 \cdot 09 \\
7 \cdot 94 \\
5 \cdot 92 \\
7 \cdot 41 \\
6 \cdot 09 \\
5 \cdot 37 \\
3 \cdot 35 \\
8 \cdot 64 \\
4 \cdot 93 \\
9 \cdot 37 \\
10 \cdot 0 \\
10 \cdot 0 \\
5 \cdot 72 \\
7 \cdot 63 \\
7 \cdot 79 \\
6.90 \\
4 \cdot 67 \\
9 \cdot 00 \\
5 \cdot 60 \\
7 \cdot 60 \\
6 \cdot 28 \\
5 \cdot 20 \\
6 \cdot 64\end{array}$ & $\begin{array}{l}2.0 \\
3.1 \\
3.4 \\
1.2 \\
1.3 \\
3.9 \\
1.2 \\
1.7 \\
0.9 \\
1.0 \\
1.1 \\
1.1 \\
1.2 \\
1.9 \\
1.9 \\
0.6 \\
1.7 \\
1.4 \\
1.0 \\
1.3 \\
9.2 \\
1.1 \\
1.9 \\
1.8 \\
1.3 \\
0.7\end{array}$ & $\begin{array}{l}\text { Cushing's } \\
\text { CP } \\
\text { CP } \\
\text { Prolactinoma } \\
\text { Prolactinoma } \\
\text { Cushing's } \\
\text { Pinealoma } \\
\text { NFA } \\
\text { NFA } \\
\text { Prolactinoma } \\
\text { NFA } \\
\text { Prolactinoma } \\
\text { NFA } \\
\text { CP } \\
\text { NFA } \\
\text { NFA } \\
\text { Cushing's } \\
\text { CP } \\
\text { Cushing's } \\
\text { Prolactinoma } \\
\text { Prolactinoma } \\
\text { Meningioma } \\
\text { NFA } \\
\text { Prolactinoma } \\
\text { CP } \\
\text { NFA }\end{array}$ & $\begin{array}{l}\text { A, B, C } \\
\text { A, B, C, D } \\
\text { A, B, C, D } \\
\text { A, B, C } \\
\text { A, C } \\
\text { A, B } \\
\text { A, B, C } \\
\text { A, B, C } \\
\text { A, B, C } \\
\text { B, C } \\
\text { A } \\
\text { C } \\
\text { A, B, C } \\
\text { A, B, D } \\
\text { A, B, E } \\
\text { A, B } \\
\text { A, B } \\
\text { A, B, D, E } \\
\text { A, E } \\
\text { A, B, D } \\
\text { A, B, D, E } \\
\text { A, B } \\
\text { A, B, D } \\
\text { D } \\
\text { D } \\
\text { B }\end{array}$ \\
\hline
\end{tabular}

BMI, body mass index; DOH, duration of hypopituitarism; CP, craniopharyngeoma; NFA, non-functioning adenoma. ${ }^{\star} \mathrm{A}$, thyroxine; $\mathrm{B}$, adrenal steroids; $\mathrm{C}$, testosterone; $\mathrm{D}$, desmopressin; $\mathrm{E}$, oestrogen/progesterone.

from the exercise tests were analysed by computer assisted methods to give exercise time, workload, heart rate $\times$ systolic blood pressure product at peak exercise, and extent of electrocardiographic ST segment change. The level of the ST segment $0.08 \mathrm{~s}$ after the J point was measured in each lead using an average beat every one minute and only planar ST segment depression $>0.1 \mathrm{mV}$ was considered to be abnormal. ST segment depression found by the average beat analysis was confirmed on the actual electrocardiogram by manual measurement.

\section{Results}

\section{PATIENT CHARACTERISTICS}

Twenty six patients (13 men and 13 women) with confirmed hypopituitarism were recruited into the study during the period December 1989-January 1991. All patients attended the endocrinology clinic in our hospital. The mean (SD) age was 46 (11) years (range 26-64 years). Table 1 shows the primary diagnosis, duration of hypopituitarism, duration of hormone replacement therapy, and other patient details. The lean body mass and body fat were 50 (9) kg (range 38-64 kg) and 30 (11) kg (range 11$55 \mathrm{~kg}$ ) respectively. The degree of growth hormone deficiency, assessed by serum concentration of insulin-like growth factor (IGF-1) was $82(45) \mu \mathrm{g} / 1$ (range $21-221 \mu \mathrm{g} / \mathrm{l}$ ). There was a significant positive correlation between IGF-1 and lean body mass in our patients $(r=$ $0.5 ; \mathrm{p}<0.01)$. No patient had a previous history of ischaemic heart disease, peripheral vascular disease, or hypertension except for one patient with Cushing's disease (patient 6) whose blood pressure had been raised before his pituitary tumour was removed but then returned to normal after the operation.

\section{ECHOCARDIOGRAPHIC AND DOPPLER}

CHARACTERISTICS

All patients had a normal left ventricular ejec- tion fraction $(67(8) \%)$ and a normal left ventricular mass index (men 101 (17) $\mathrm{g} / \mathrm{m}^{2}$ range $76-132 \mathrm{~g} / \mathrm{m}^{2}$; women $84(20) \mathrm{g} / \mathrm{m}^{2}$ range $56-119 \mathrm{~g} / \mathrm{m}^{2}$ ) but the distribution was skewed towards the lower end of the normal range (skew 0.25). Patients who had Cushing's disease did not have higher left ventricular mass indexes. Table 2 shows the other echocardiographic and Doppler characteristics. Compared with the age related reference values established by previous investigators, ${ }^{1314}$ thirteen patients $(50 \%)$ had an abnormally prolonged isovolumic relaxation time (112 (15) $\mathrm{ms}$ ) and eight ( $31 \%$ ) had both an increased isovolumic relaxation time $(103(8) \mathrm{ms})$ and evidence of abnormal left ventricular filling (E/A ratio $1.06(0.25)$ table 3$)$. There was significant correlation between left ventricular mass and serum IGF-1 ( $\mathrm{r}=0.45 ; \mathrm{p}<0.02)$. Left ventricular mass and left ventricular filling were related to lean body mass $(r=0.78 p<$ $0.0001 ; r=-0.63 p<0.001$ ) (figure 2A-C) There was no relation between left ventricular mass and duration of hypopituitarism.

\section{EXERCISE ASSESSMENTS}

The mean exercise duration during the Bruce protocol was $8.6(3.6)$ minutes. The exercise test was terminated because of leg weakness in seven patients, by shortness of breath in eight

Table 2 Echocardiographic and Doppler characteristics of study patients

\begin{tabular}{lcc}
\hline Variable & Mean $(S D)$ & \multicolumn{1}{c}{ Range } \\
\hline LV septum (cms) & $0 \cdot 85(0 \cdot 2)$ & $0 \cdot 5-1 \cdot 1$ \\
LV posterior wall (cms) & $0 \cdot 84(0 \cdot 2)$ & $0 \cdot 6-1 \cdot 1$ \\
LV internal diameter (cms) & $4 \cdot 82(0 \cdot 4)$ & $4 \cdot 1-5 \cdot 6$ \\
LV mass (male)(g) & $212(49)$ & $138-323$ \\
LV mass (female) (g) & $148(42)$ & $92-231$ \\
IVRT (ms) & $103(16)$ & $72-140$ \\
E (cm/s) & $64(13)$ & $38-87$ \\
A (cm/s) & $55(10)$ & $36-71$ \\
E/A ratio & $1 \cdot 18(0.31)$ & $0 \cdot 74-1.94$ \\
\hline
\end{tabular}

V , left ventricle; IVRT, isovolumic relaxation time; $E$, early filling velocity; $A$, atrial filling velocity. 
Table 3 Details of patients with abnormal left ventricular diastolic function

\begin{tabular}{llllllll}
\hline Patient & $\begin{array}{l}\text { Age } \\
(y \mathbf{r})\end{array}$ & $\begin{array}{l}\text { Heart } \\
\text { rate }\end{array}$ & $\begin{array}{l}\text { IVRT } \\
(\mathrm{ms})\end{array}$ & $\begin{array}{l}E \\
(\mathrm{~cm} / \mathrm{s})\end{array}$ & $\begin{array}{l}A \\
(\mathrm{~cm} / \mathrm{s})\end{array}$ & $E / A$ & $\begin{array}{l}\text { Max ST depression } \\
\text { on exercise }(\mathrm{mV})\end{array}$ \\
\hline 1 & 34 & 70 & 108 & 66 & 48 & $1 \cdot 37$ & None \\
3 & 47 & 65 & 96 & 66 & 58 & $1 \cdot 15$ & $0 \cdot 22$ \\
7 & 27 & 77 & 92 & 78 & 62 & $1 \cdot 26$ & $0 \cdot 13$ \\
8 & 45 & 69 & 111 & 49 & 62 & $0 \cdot 8$ & $0 \cdot 19$ \\
9 & 59 & 78 & 108 & 39 & 51 & $0 \cdot 77$ & None \\
11 & 44 & 63 & 94 & 72 & 61 & $1 \cdot 17$ & None \\
12 & 41 & 74 & 112 & 48 & 65 & $0 \cdot 74$ & None \\
18 & 26 & 73 & 104 & 75 & 59 & $1 \cdot 25$ & None \\
\hline
\end{tabular}

IVRT, isovolumic relaxation time; $E$, early filling velocity; $A$, atrial filling velocity.

patients, and by exhaustion in 11 patients. No patient developed chest pain during exercise. A significant correlation was seen between serum IGF-1 and the rate-pressure product (systolic blood pressure $\times$ heart rate) at peak exercise $(r=0.47 ; p<0.01$; fig 2D) but not with exercise duration $(r=0 \cdot 1 ; p=N S)$. Baseline electrocardiograms were normal in all patients except for patients 8 and 15 who had minor ST segment abnormalities in the lateral chest leads. Seven patients developed planar ST segment depression $>0.1 \mathrm{mV}$ during exercise testing (maximum ST segment depression in these seven patients was $0 \cdot 18(0 \cdot 03) \mathrm{mV})$. In five of these patients the ST segment depression occurred at a high workload with immediate resolution after exercise. Two patients developed ST segment depression after a few minutes of exercise with slow resolution during the post-exercise period. Subsequent coronary angiography showed no abnormality of the epicardial coronary arteries. Exercise-induced ST segment depression was not related to the severity or duration of growth hormone deficiency or to serum cholesterol concentration. Three of these seven patients also had abnormal left ventricular diastolic function.

\section{Discussion}

The principal findings of this study were firstly that in patients with treated hypopituitarism but without growth hormone replacement therapy the left ventricular mass and maximum cardiac work achieved on exercise were inversely related to the degree of growth hormone deficiency. Second, left ventricular diastolic dysfunction seems to be a frequent finding in these patients and furthermore these patients often have ischaemia-like ST segment changes during exercise testing.

All of the patients in this study had a normal left ventricular mass index with a trend towards the lower end of the normal range. The relation between left ventricular mass and body weight/ lean body weight seen in this study is similar to that reported in healthy individuals. ${ }^{15}$ However, the relation between left ventricular mass and the degree of growth hormone deficiency is surprising, because it suggests that growth hormone may still be necessary for the maintenenace of cardiac size in adulthood. Growth hormone administration in adult rats increased left ventricular mass in proportion to the observed increase in body weight. ${ }^{16}$ In humans, however, four months of growth hormone replacement therapy given to growth hormone deficient adults had no significant effect on left ventricular mass. ${ }^{17}$ It is possible, however, that left ventricular mass may increase with longer term replacement therapy. Whether our measurements of left ventricular mass are indeed "normal" for these patients is open to debate; however, the inverse relation between the degree of growth hormone deficiency and peak cardiac work on exercise (rate-pressure product) suggests that the exercise capacity of the heart is impaired in hypopituitarism. Nonetheless, the mechanism for exercise
Figure 2 (A) Relation between serum IGF-1 and left ventricular mass $(L V M),(B)$ relation between lean body mass and $L V M$,

(C) relation between lean body mass and left ventricular filling ( $E / A$ ratio), (D) relation between serum IGF-1 and the rate-pressure product. The regression line and its 95\% confidence limits are shown for each scattergram.
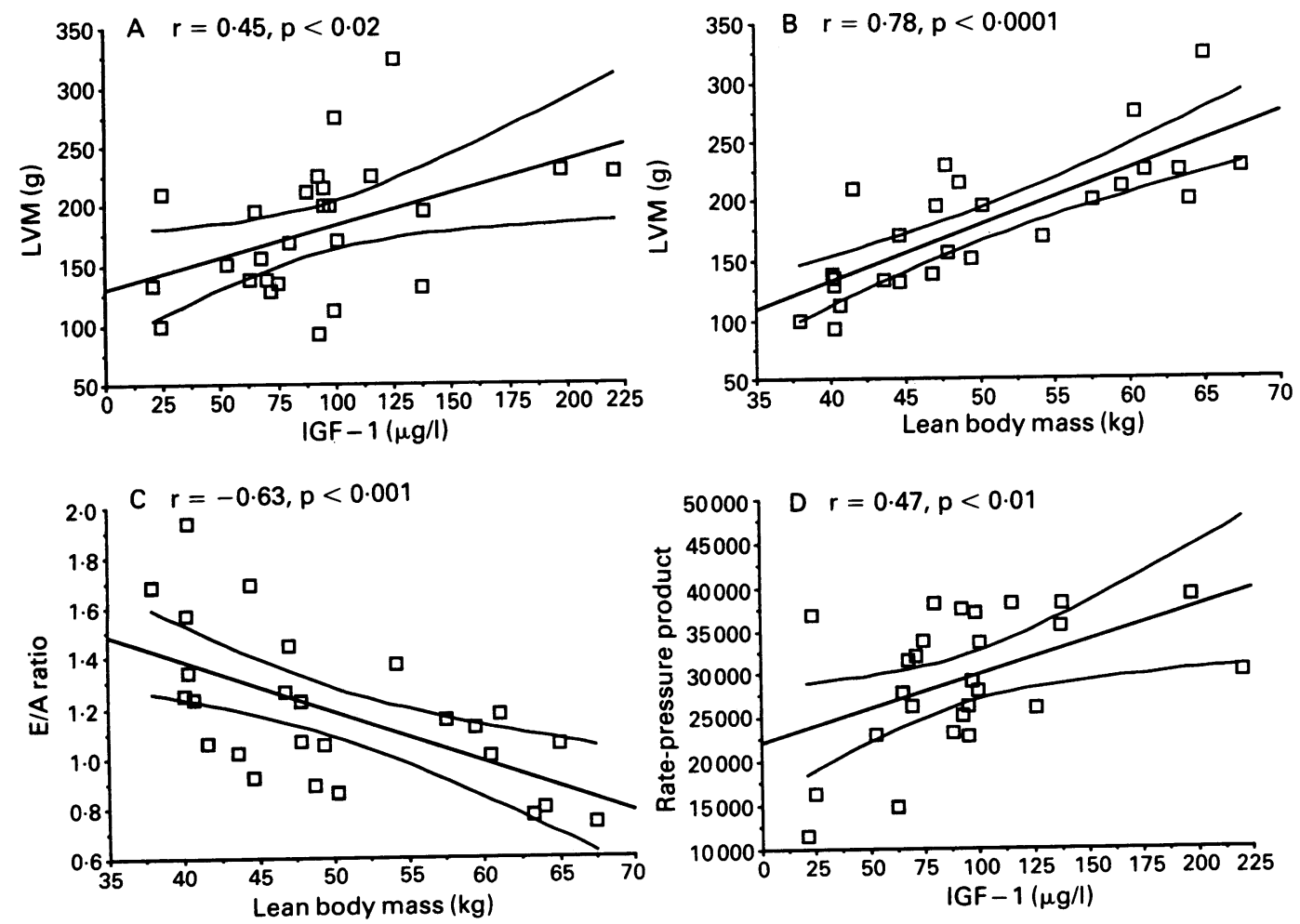
limitation in this patient population is complex and probably relates to a combination of peripheral muscle atrophy, deconditioning, and changes in cardiac function. In the present study, only seven of the 26 patients had their exercise test stopped because of leg weakness while the rest were stopped by shortness of breath or extreme exhaustion.

The frequent finding that abnormalities of left ventricular diastolic function in the presence of normal left ventricular systolic function in patients with hypopituitarism has not been described before. It has been suggested that these abnormalities are a possible precursor of left ventricular systolic failure and may be the earliest manifestations of cardiac failure. ${ }^{18}$ These abnormalities may explain the increased incidence of heart failure in patients with hypopituitarism. ${ }^{2}$ Whether growth hormone replacement therapy will improve this abnormality is not known. However, in healthy people growth hormone therapy increased myocardial contractility and cardiac output ${ }^{19}$ and therefore it might be able to reverse the diastolic abnormalities observed in this study. Growth hormone therapy was shown to benefit one growth hormone deficient patient with severe cardiac failure. ${ }^{20}$

Nor has the increased incidence of ST segment depression on exercise, similar to that seen in patients with coronary artery disease, been reported before in patients with hypopituitarism. Most of these patients developed these abnormalities at a high workload; however, two patients did have ST segment depression at a low workload and subsequent coronary angiography was normal. Although these may have been false positive electrocardiographic responses to exercise testing, it may in light of the known increased cardiovascular mortality in these patients suggest that they have small coronary vessel disease or some undisclosed form of myocardial disease. McHenry and colleagues reported that symptom free patients who had not had coronary angiography had about a $40 \%$ chance of developing coronary artery disease over a 14 year period if they had an ischaemic-type response to exercise. ${ }^{21}$ If the outcome were similar in our patients, with their additional risk of increased serum cholesterol, this could explain the increased incidence of myocardial infarction observed in patients with treated hypopituitarism. $^{2}$

We cannot be certain that inadequate replacement therapy of other pituitary dependent hormones-for example, thyroxine, cortisol, and oestrogen therapy, was not the reason for the abnormal cardiac findings in our patients. However, all our patients had been euthyroid for at least one year and had thyroxine $\left(T_{4}\right)$ concentrations within the normal range. Patients with Cushing's disease had been cured for at least three years and sex hormones were prescribed to all patients. In addition no patients had hypertension or diabetes mellitus.

Though we did not study age matched controls our criteria for abnormality were strictly defined and lay outside the $95 \%$ confidence intervals of the normal range reported by others.

In conclusion, we found that patients with treated hypopituitarism had abnormalities of cardiac structure and function that may explain the increased incidence of cardiovascular mortality observed in these patients. The relation with the degree of growth hormone deficiency may have implications for growth hormone replacement therapy in adults.

We thank the Coronary Flow Trust and Novo Nordisk SA for financial support. The Hormone Distribution Program of NIDDK (National Institutes of Health, Bethesda, USA) for supplying IGF-1 antiseum and Mr V Anyoaku, Mr A Henderson and Mr C Freemantle for biochemical and technical support.

1 Besser GM. Anterior pituitary. In: Hall R, Besser GM, eds. Fundamental of clinical endocrinology. London: Churchill Livingstone, 1989:1-30.

2 Rosen T, Bengtsson B. Premature mortality due to cardiovascular disease in hypopituitarism. Lancet 1990;336: 285-8.

3 Saloman F, Cuneo RC, Hesp R, Sonksen PH. The effects of treatment with recombinant human growth hormone on body composition and metabolism in adults with orowth body composition and metabolism in adults with growth

4 Larsson B, Svardsudd K, Welin L, Wilhelmsen L, Bjorntorp P, Tibblin G. Abdominal adipose tissue distribution, torp P, Tibblin G. Abdominal adipose tissue distribution, obesity and risk of cardiovascular disease and death: 13 year follow-up of participants in

5 Lapidus L, Bengtsson C, Larrson B, Pennert K, Rybo E, Sjostrom L. Distribution of adipose tissue and risk of cardiovascular disease and death: a 12 year follow-up of participants in the population study of women in Gothenberg, Sweden. BMJ 1984;289:1257-61.

6 Merimee T, Hollander W, Fineberg E. Studies of hyperlipidaemia in the hGH-deficient state. Metabolism 1972; 21:1053-61.

7 Blackett PR, Weech PK, McConathy WJ, Fesmire JD. Growth hormone in the regulation of hyperlipidaemia. Metabolism 1982;31:117-20.

8 Boddy K, King PC, Hume R, Weyers E. The relationship of total body potassium to height, weight and age in normal adults. J Clin Pathol 1972;25:512-7.

9 Teale JD, Marks V. The measurement of insulin-like growth factor 1: clinical applications and significance. Ann Clin Biochem 1986;23:413-24.

10 Foale R, Nihoyannopoulos P, McKenna W, et al. Echocardiographic measurement of the normal adult right ventricle. Br Heart J 1986;56:33-44.

11 Helak JW, Reichekk N. Quantitation of human left ventricular mass and volume by two-dimensional echocardiography: in vitro validation. Circulation 1981; 63:1398-407.

12 Spirito P, Maron BJ. Influence of aging on Doppler echocardiographic indices of left ventricular diastolic function. Br Heart J 1988;59:672-9.

13 Gardin JM, Rohan MK, Davidson, et al. Doppler transmitral flow velocity parameters: relationship between age, body surface area, blood pressure and gender in normal subjects. Am J Noninvas Cardiol 1987;1:3-10.

14 Bruce RA, Blackmon JR, Jones JW, Strait G. Exercise testing in adult normal subjects and cardiac patients. Pediatrics 1963;32:742-56.

15 Devereux RB, Lutas EM, Casale PN, et al. Standardisation of $M$ mode echocardiographic left ventricular anatomic of $M$ mode echocardiographic left ventricular anat

16 Lei LQ, Rubin SA, Fishbein MC, Cardiac architectural changes with hypertrophy induced by excess growth
ches hormone in rats. Lab Invest 1988;59:357-62.

17 Jorgensen JOL, Pedersen SA, Thuesen L, et al. Beneficial effects of growth hormone treatment in GH-deficient adults. Lancet 1989;i:1221-5.

18 Dougherty AH, Naccerelli GV, Gray EL, Hicks CH, Golstein RA. Congestive heart failure with normal systolic function. Am J Cardiol 1987;54:778-82.

19 Thuesen L, Christiansen JS, Sorensen KE, Jorgensen JOL, Orskov H, Henningsen P. Increased myocardial contractility following growth hormone administration in normal man: an echocardiographic study. Dan Med Bull 1988; 35:193-6.

20 Cuneo RC, Wilmhurst P, Lowy C, McGauley G, Sonksen PH. Cardiac failure responding to growth hormone. Lancet 1989;i:838-9.

21 McHenry PL, O'Donnell J, Morris SN, Jordan JJ. The abnormal exercise electrocardiogram in apparently healthy men: a predictor of angina pectoris as an initial 1984;70:547-52. 